\title{
Kinetic Analysis on Effect of Poly(4-vinyl phenol) on Complex-Forming Blends of Poly(L-lactide) and Poly(D-lactide)
}

\author{
By Shu-Hsien LI and Eamor M. WoO*
}

\begin{abstract}
Differential scanning calorimetry (DSC), Fourier transformed infrared spectroscopy (FT-IR) and polarized optical microscopy (POM) characterizations were performed to reveal interaction between amorphous poly(p-vinyl phenol) (PVPh) and crystalline stereocomplex of poly(L-lactic acid) (PLLA) and poly(D-lactic acid) (PDLA). The negative value of the interaction parameter $\chi_{12}$ clearly confirms a thermodynamic miscibility in the ternary blend. At low contents, PVPh is well dispersed in the ternary blends, but PVPh may aggregate to nanodomains by self-associated hydrogen-bonding upon annealing. In addition, PVPh serves as an effective agent in reducing the spherulite sizes of the PLLA/PDLA crystals, which may be favorable in controlling the macroscopic properties. The Avrami and Tobin kinetic analysis methods were carried out to analyze the nonisothermal crystallization data, and the results showed that the ternary blends with an optimal range of 2$10 \mathrm{wt} \% \mathrm{PVPh}$ were faster in the crystallization rate and smaller in the spherulite size than those with no PVPh or with PVPh contents greater than $10 \mathrm{wt} \%$. Ternary blend containing higher PVPh contents may form large phase-separated domains and growth of the stereocomplex is hindered under the nonisothermal crystallization condition.
\end{abstract}

KEY WORDS: PLA Complex / PVPh / Blends / Kinetic Analysis /

Polymer blends with several percents of modifiers in polymer matrices are of interest because a small amount of modifier loadings may lead to finer modifier dispersion, with sizes approaching possibly nanodispersed domains (less than $100 \mathrm{~nm})$. It is expected that the inherently high surface areavolume ratio of the nanodomains plays a key role in enhancing the desired properties. On the other hand, the nanodispersed domain may significantly change the properties of the matrix, for example, the crystallization behavior for semicrystalline polymers. Nanostructured poly(vinylidene fluoride) (PVDF)/ acrylic rubber blends have been reported that the acrylic nanodomains accelerate the PVDF crystallization and reduce the size of PVDF spherulites in the blends. ${ }^{1}$

Some low-molecular weight organic compounds are known to form complexes. However, by comparison, stereocomlexation is still a rare yet interesting phenomenon in polymers. Several cases have been found by blending tactic polymers of opposite configurations, for examples, isotactic and syndiotactic poly(methyl methacylate)s, ${ }^{2,3}$ polythiiranes, ${ }^{4}$ polyoxiranes, ${ }^{5}$ polylactones. ${ }^{6,7}$ The common features of all these systems are that crystallization of enantiomeric polymer chains leads to packing of two different molecular chains into a common crystal lattice, in which the two chains are more densely packed than those of the parent homopolymer crystal lattices. Consequently, enantiomeric polymer blends with a stereocomplex crystal structure show higher melting temperatures, leading to different physical and mechanical properties in comparison to their parent homopolymers.

Since the discovery by Ikada et al. ${ }^{8}$ of a stereocomplex from equimolar (1:1) mixtures of poly(L-lactic acid) (PLLA) and poly(D-lactic acid) (PDLA) in melts or solutions, numerous studies have been performed on formation and crystallization of the stereocomplexes as well as its crystalline structures, morphology, and physical properties..$^{9-11}$ The blend of PLLA and PDLA produces a stereocomplex with melting temperature of $220-230^{\circ} \mathrm{C}$, which is $50^{\circ} \mathrm{C}$ higher than the melting points of the individual enantiomeric polymers. ${ }^{8}$ Several mechanisms have been proposed and tested. Tsuji et al. ${ }^{12}$ have speculated that there are peculiarly strong interactions between the leftand right-handed helices of PLLA and PDLA in the stereocomplex. Birzzolara et al. ${ }^{10}$ have proposed that van der Waals interactions are formed between the opposite oxygen atoms and hydrogen atoms, and such interactions cause the stabilization of the $3_{1}$ helix and higher melting point of the complex. One interesting feature is the capacity of the enantiomeric blends of PLLA and PDLA to form a stereocomplex with higher crystal stability and crystalline ability than the individual PLLA or PDLA. ${ }^{8}$ The most stable crystal unit cell of PLLA has been proposed to consist of a pair of $10_{3}$ helics, whereas the chains in the stereocomplex have been shown to exhibit $3_{1}$ helics of an opposite configuration. ${ }^{9,10,13}$ It is presumed that the packing of the stereocomplex $33_{1}$ helices is stabilized by van der Waals interactions leading to the observed increase in melting temperature. Stereocomplexes are noted with interests because of their potential as matrices for controlled drug delivery systems, tissue engineering, and other biomedical purpose. A recent series of works on the use of poly(lactic acid) stereocomplex has evidenced the potential applications of these systems for drug-controlled release and stabilization of peptide and protein drugs. ${ }^{14-18}$

Although investigations on complexes of PLLA/PDLA binary blends are numerous as cited above; however, effects of 
a third polymer introduced to form ternary blends, consisting of PLLA, PDLA, and the third component, have not received much attention. Fukushima et al. ${ }^{19}$ have reported that stereoblock poly(lactic acid) (sb-PLA) is added into an equimolar polymer blend system of PLLA and PDLA to study its effect on the stereocomplex formation of PLLA and PDLA. In their study, the ternary polymer blends were prepared by casting a polymer solution of sb-PLA, PLLA and PDLA with different compositions. Upon increasing the content of sb-PLA in the blend, the stereocomplex crystallization is driven to a higher degree, while the formation of homo-chiral crystals in decreased. ${ }^{19}$

Solvent-cast blends of poly(L-lactide) (PLLA) with poly(4-vinyl phenol) (PVPh) have been shown to be partially miscible. $^{20,21}$ However, miscibility has been found in all compositions range for the PLLA/PVPh blends prepared by solution/precipitation methods. Weak hydrogen-bonding interaction exists between the carbonyl groups of PLLA and the hydroxyl group of PVPh. ${ }^{20,21}$ The growth of PLLA spherulites from the melt under isothermal conditions is slowed down by PVPh. When the PVPh content is above $40 \mathrm{wt} \%$, crystallization of PLLA does not occur under isothermal conditions. ${ }^{20,21}$ Moreover, blends of amorphous poly(D,L-lactide) (PDLLA) with amorphous PVPh by solvent casting are phase separated in blends with high PVPh contents. ${ }^{22}$

It was of interest to investigate effects of a miscible polymer on the stereocomplexation behavior of PLLA and PDLA in a blend system. Poly(4-vinyl phenol) (PVPh), with a hydroxyl group at the pendant phenyl ring, is capable of interacting with proton-accepting functional groups with both PLLA and PDLA. It was of interest to explore the phase behavior, interactions, and crystallinity in PLLA/PDLA/PVPh ternary blend systems. Modifications of morphology and properties of complexes in PLLA/PDLA blends by introducing PVPh were probed and interpreted.

\section{EXPERIMENTAL}

\section{Materials and Sample Preparation}

Poly(L-lactide) (PLLA) was obtained from Fluka, Inc. (Switzerland), with weight-average molecular weight of $152,000 \mathrm{~g} / \mathrm{mol} \quad$ and $\quad T_{\mathrm{g}}$ (onset) $=57^{\circ} \mathrm{C}$. Poly(D-lactide) (PDLA) was obtained from Fluka, Inc. (Switzerland), with weight-average molecular weight of $124,000 \mathrm{~g} / \mathrm{mol}$ and $T_{\mathrm{g}}$ (onset) $=54^{\circ} \mathrm{C}$. PLLA and PDLA are both semicrystalline with melting temperature of $170{ }^{\circ} \mathrm{C}$. Poly(4-vinyl phenol) $(\mathrm{PVPh})$ with $M_{\mathrm{w}}=22,000 \mathrm{~g} / \mathrm{mol}$, an amorphous polymer with $T_{\mathrm{g}}$ of $148^{\circ} \mathrm{C}$, was obtained from Polysciences, Inc. (USA).

Ternary blend of PLLA, PDLA and PVPh were prepared by solvent casting using dioxane as a good mutual solvent. These polymers with concentration of $2 \mathrm{~g} / 100 \mathrm{~mL}$ in solvent were mixed in desired proportions, well stirred, and cast onto glass dishes at $80^{\circ} \mathrm{C}$. The blend ratios of the polymers were defined by weight ratios of the polymers. The mixing ratios of (PLLA/ PDLA)/PVPh were (50/50)/0, (49/49)/2, (47.5/47.5)/5, (45/
45)/10 and (40/40)/20. The content of PVPh was changed but the PLLA/PDLA ratio was fixed at equivalent weight $(1 / 1)$ in the ternary blends. In the following texts, the blend compositions, (PLLA/PDLA)/PVPh with (50/50)/0, (49/49)/2, (47.5/ 47.5)/5, (45/45)/10 and (40/40)/20 are designated as 100/0, $98 / 2,95 / 5,90 / 10$ and 80/20, respectively. The solvent was evaporated for $24 \mathrm{~h}$, and then the thin films were further dried in vacuum at $100^{\circ} \mathrm{C}$ for 1 week.

\section{Apparatus and Procedures}

A polarized-light microscope (Nikon Optiphot-2, POL), equipped with a CCD digital camera and image software, was used for characterizing optical homogeneity and/or crystalline morphology of the blends. A small quantity of the blend samples was transferred to between micro-glass slides, heated and pressed into thin film on a heating stage, and examined using the optical microscope.

$T_{\mathrm{g}}$ transitions of the blend samples were measured with a differential scanning calorimeter (Diamond DSC, PerkinElmer) equipped with an intracooler for subambient temperature down to $-70^{\circ} \mathrm{C}$. Prior to DSC runs, the temperature and heat of transition of the instrument were calibrated with indium and zinc standards. During thermal annealing or scanning, a continuous nitrogen flow in the DSC sample cell was maintained to ensure minimal sample degradation. For determining the $T_{\mathrm{g}}$ transition temperatures, cold-crystallization and melting transitions were made at a heating rate of $20^{\circ} \mathrm{C} / \mathrm{min}$. To observe the equilibrium melting temperature of crystalline polymer in either binary or ternary blends, the specimens were first hold at the temperature of $10^{\circ} \mathrm{C}$ above melting point of crystalline polymer to eliminate the crystalline residues. The polymer samples were then quenched to the desired crystallization temperature, then isothermally crystallized until complete crystallization, and finally scanned at a rate of $10^{\circ} \mathrm{C} / \mathrm{min}$. The nonisothermal crystallization behaviors of the blends were first heated to $235^{\circ} \mathrm{C}$ then cooled to $100^{\circ} \mathrm{C}$ at constant cooling rates of $2.5,5,10,20,40^{\circ} \mathrm{C} / \mathrm{min}$. The exothermic curves of heat flow as a function of temperature were recorded and investigated.

FT-IR spectroscopy (Nicloet Magna-560, USA) was used for investigating the intermolecular interaction between constituents. Spectra were obtained at $4 \mathrm{~cm}^{-1}$ resolution and averages were obtained from 64 scans in the standard wavenumber range from $4000 \mathrm{~cm}^{-1}$ to $400 \mathrm{~cm}^{-1}$. All the blending samples for FT-IR analysis were mold as thin films that were sandwiched between two $\mathrm{KBr}$ pellets. For IR experiments monitoring the melt crystallization processes of the ternary blends, the $\mathrm{KBr}$ pellets with a solution-cast film was set on a variable-temperature control cell (HT-32, Thermo SpectraTech), which was positioned inside the sample compartment of FT-IR spectrometer. The samples were first heated to $240^{\circ} \mathrm{C}$ at $10^{\circ} \mathrm{C} / \mathrm{min}$ to melt the polymer and completely erase the thermal history. Then, it was cooled to $200^{\circ} \mathrm{C}$ at $-5^{\circ} \mathrm{C} / \mathrm{min}$ for the isothermal melt crystallization. IR spectra of the samples held at $200^{\circ} \mathrm{C}$ were collected with 4 min interval during the annealing process. 


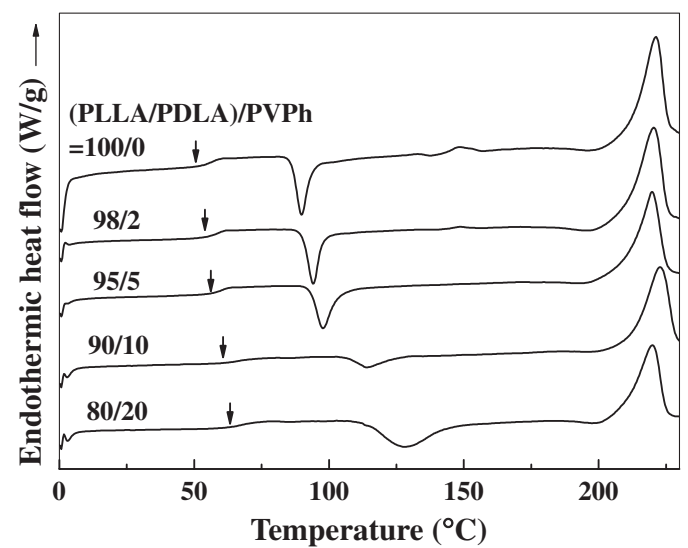

Figure 1. DSC thermograms (2nd scans) for ternary (PLLA/PDLA)/PVPh blend of different compositions as labeled on traces.

Wide-angle X-ray instrument (WAXD) was Shimadzu XRD-6000 with copper $\mathrm{K}_{\mathrm{a}}$ radiation $(30 \mathrm{kV}$ and $40 \mathrm{~mA})$ and a wavelength of $1.542 \AA$. The scanning $2 \theta$ angle range was from $5^{\circ}$ to $40^{\circ}$ with a scanning rate of $2^{\circ} \mathrm{C} / \mathrm{min}$.

\section{RESULTS AND DISCUSSION}

\section{Miscibility between the Crystalline Complex and PVPh}

PLLA/PDLA(1/1) blend can form a stereocomplex crystallization with a melting point of $220^{\circ} \mathrm{C}$ and an onset glass transition temperature of $50^{\circ} \mathrm{C}$ as shown in Figure 1. In addition, an exothermic peak corresponding to the cold crystallization of stereocomplex is about $90^{\circ} \mathrm{C}$. The figure also shows the DSC thermograms for the ternary (PLLA/ $\mathrm{PDLA} / \mathrm{PVPh}$ blends with increasing $\mathrm{PVPh}$ contents in the compositions. The (PLLA/PDLA)/PVPh blends (with 2$20 \mathrm{wt} \% \mathrm{PVPh}$ ) show a single glass transition temperature close to that of the pure PLA, which increases with increasing $\mathrm{PVPh}$ content. It indicates that the ternary blends are miscible over this composition range. In addition, the only endothermic peak noticed around $220^{\circ} \mathrm{C}$ can be assigned to melting of stereocomplex crystallites. Note the melting point to neat PLLA (or PDLA) is about $170^{\circ} \mathrm{C}$. No clear melting behavior change was found upon addition of small amount of $\mathrm{PVPh}$, but the enthalpy of melting slightly decreased for higher amount of $\mathrm{PVPh}$ than that of blend without PVPh. Furthermore, the cold crystallization temperature of stereocomplex shifts to high temperature range in the ternary blends compared with that of the neat stereocomplex. The presence of high glass transition component $\mathrm{PVPh}$ in the blends increases the glass transition temperature of the ternary blends, resulting in the decrease of cold crystallization of stereocomplex. This is typical thermal behavior for a miscible blend with $\mathrm{PVPh}$.

Figure 2 shows Hoffman-Weeks plots $\left(T_{\mathrm{m}}\right.$ vs. $\left.T_{\mathrm{c}}\right)$ for (PLLA/PDLA)/PVPh blend of various compositions and a plot according to Flory-Huggins theory for estimating the polymer-polymer interaction parameter. It must be noted that the PLLA/PDLA complex was treated as a single component, (a)
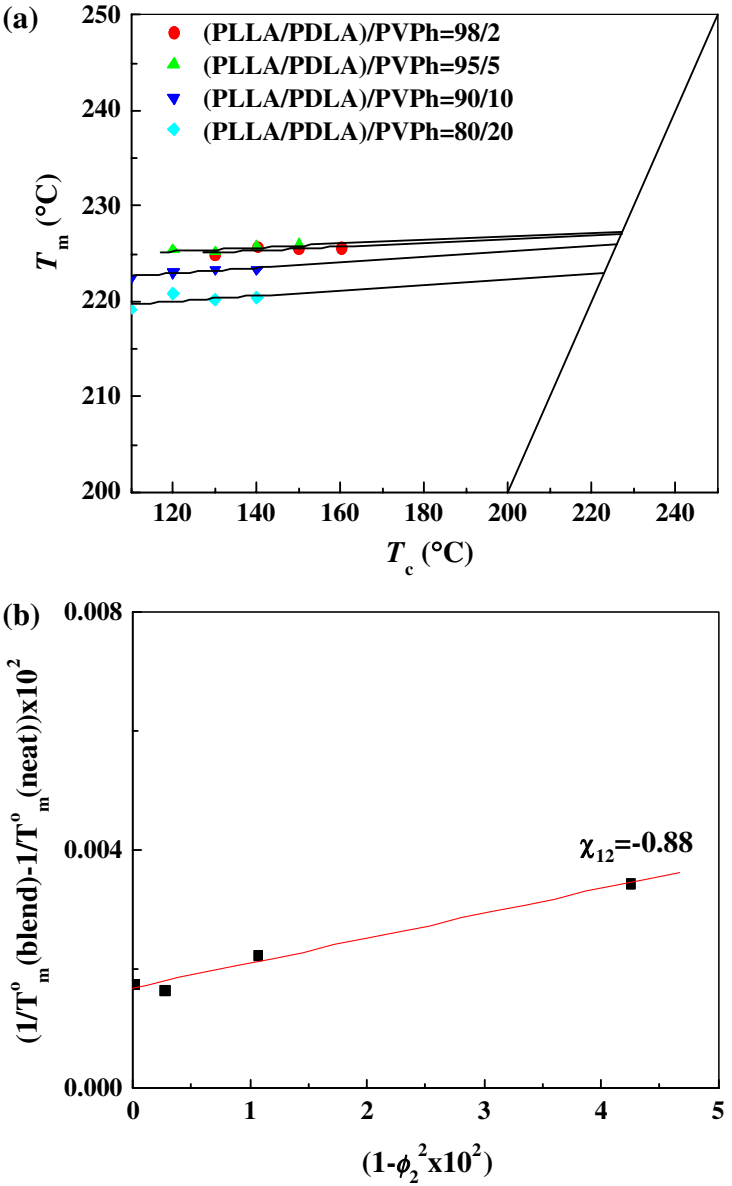

Figure 2. (a) Hoffman-Weeks plots $\left(T_{\mathrm{m}}\right.$ vs. $T_{\mathrm{c}}$ ) for (PLLA/PDLA)/PVPh blend of various compositions crystallized at selected $T_{\mathrm{c}}$ all for $4 \mathrm{~h}$, and (b) equilibrium melting points of (PLLA/PDLA)/PVPh ternary blends according to the Flory-Huggins relationship.

whose melting point depression by the amorphous $\mathrm{PVPh}$ polymer was measured. Hoffman and Weeks ${ }^{23}$ have shown a relationship between the melting point $\left(T_{\mathrm{m}}\right)$ and the isothermal crystallization temperature $\left(T_{\mathrm{c}}\right)$ :

$$
T_{\mathrm{m}}=\eta T_{\mathrm{c}}+\left(1-T_{\mathrm{c}}\right) T_{\mathrm{m}}^{\mathrm{o}}
$$

where $T_{\mathrm{m}}{ }^{\circ}$ is the equilibrium melting point and $\eta$ is regarded as a measure of the stability of the crystals undergoing the melting process. The $T_{\mathrm{m}}{ }^{\mathrm{o}}$ can be obtained from the intersection of the line with $T_{\mathrm{m}}=T_{\mathrm{c}}$ equation. The decrease in the $T_{\mathrm{m}}{ }^{\mathrm{o}}$ obtained upon addition of PVPh to (PLLA/PDLA) suggests the miscibility of the system.

The equilibrium melting point obtained in this study was analyzed by the Nishi-Wang equation ${ }^{24}$ based on the FloryHuggins theory: ${ }^{25}$

$$
\left(\frac{1}{T_{\mathrm{m}}}-\frac{1}{T_{\mathrm{m}}^{\mathrm{o}}}\right)=-\left(\frac{R V_{2}}{\Delta H_{f} V_{1}}\right)\left[\frac{\ln \phi_{2}}{n_{2}}+\left(\frac{1}{n_{2}}-\frac{1}{n_{1}}\right) \phi_{1}+\chi \phi_{1}^{2}\right]
$$

In the present case of two polymers, both $\mathrm{n}_{1}$ and $\mathrm{n}_{2}$ are much larger than unity. Therefore, the equation reduces to 


$$
\left(\frac{1}{T_{\mathrm{m}}}-\frac{1}{T_{\mathrm{m}}^{\mathrm{o}}}\right)=-\left(\frac{R V_{2}}{\Delta H_{f} V_{1}}\right) \chi \phi_{1}^{2}
$$

where $T_{\mathrm{m}}$ and $T_{\mathrm{m}}{ }^{\mathrm{o}}$ are the equilibrium melting points of the stereocomplex in ternary blends or in binary blends, respectively. The subscript " 1 " indicates the non-crystallizing polymer $(\mathrm{PVPh})$, and " 2 " indicates the crystallizing polymer (the PLLA/PDLA crystalline complex), and $V_{\mathrm{i}}$ are the molar volumes of the repeat units of the polymers. $\Delta H_{\mathrm{f}}$ is the heat of fusion of the fully crystalline polymer, and $\phi$ is the volume fraction. By plotting the left-hand-side versus the right-handside term of the above equation, the interaction parameter $\chi_{12}$ was determined from the slope of the plot. The physical constants for the calculation were $V_{1}=100 \mathrm{~cm}^{3} \mathrm{~mol}^{-1}$, $V_{2}=53.3 \mathrm{~cm}^{3} \mathrm{~mol}^{-1}, \Delta H_{\mathrm{f}}=142 \mathrm{Jg}^{-1}$ for the PLA stereocomplex. Figure 2(b) shows the plot for calculation the $\chi_{12}$. Furthermore, the interaction energy density $B_{12}$ could be calculated by the equation $\chi_{12}=\frac{B_{12} V_{1}}{R T_{\mathrm{m}}^{\circ}}$ to quantitatively estimate the interaction in the blends.

The value of interaction strength (dimensionless) obtained from result in Figure 2 is $\chi_{12}=-0.88$, from which the energy density (energy per volume) could be calculated to be $B_{12}=$ $-8.74 \mathrm{cal} / \mathrm{cm}^{3}$. The negative value of the interaction parameter $\chi_{12}$ clearly confirms a thermodynamically miscible blend. Note that $B_{12}=-8.8 \mathrm{cal} / \mathrm{cm}^{3}$ is reported for the binary PLLA/ PVPh blend prepared by solution/precipitation method. ${ }^{21}$ The interaction between PVPh and the PLLA/PDLA complex is not much different from that between PVPh and PLLA, indicating that the crystalline-amorphous (PVPh-crystals) equilibrium may be similar regardless of complex forming. The value of interaction is however, lower than that found in PHB $/$ PVPh $\left(B_{12}=-12.77 \mathrm{cal} / \mathrm{cm}^{3}\right)^{26}$ and PCL $/$ PVPh $\left(B_{12}=\right.$ $\left.-9.87 \mathrm{cal} / \mathrm{cm}^{3}\right),{ }^{27}$ indicating that the polymer-polymer interaction in the partially miscible ternary PVPh/PLLA/PDLA blend is weaker than that in the fully miscible $\mathrm{PHB} / \mathrm{PVPh}$ and PCL/PVPh blends.

FTIR was used to reveal specific interactions between the amorphous PVPh and the crystalline PLLA/PDLA complex. Figure 3 shows the hydroxyl $(-\mathrm{OH})$ stretching and carbonyl $(\mathrm{C}=\mathrm{O})$ stretching region in the blends. Neat $\mathrm{PVPh}$ shows two distinct bands in $\mathrm{OH}$ stretching region. A broad band centered at $3355 \mathrm{~cm}^{-1}$ can be attributed to the hydrogen-bonded hydroxyl group (self-association), and a relatively narrow band at $3525 \mathrm{~cm}^{-1}$, assigned to the free (non-association) hydroxyl groups. Upon mixing with (PLLA/PDLA) and PVPh, the intensity of the free hydroxyl group band increases with increasing $\mathrm{PVPh}$ content and the hydrogen-bonded hydroxyl group band of $\mathrm{PVPh}$ disappears, indicating no hydrogenbonding interactions between the hydroxyl groups of PVPh and carbonyl groups of PLLA and PDLA. Note that the absence of hydrogen-bonding interaction in the blends might also be attributed to the low content of PVPh. Besides the hydroxylstretching region, the carbonyl-stretching band in the FTIR spectrum is also sensitive to hydrogen-bonding formation. In the figure, the carbonyl group (at $1755 \mathrm{~cm}^{-1}$ ) also shows no hydrogen-bonded $\mathrm{C}=\mathrm{O}$ groups stretching bands. There is no

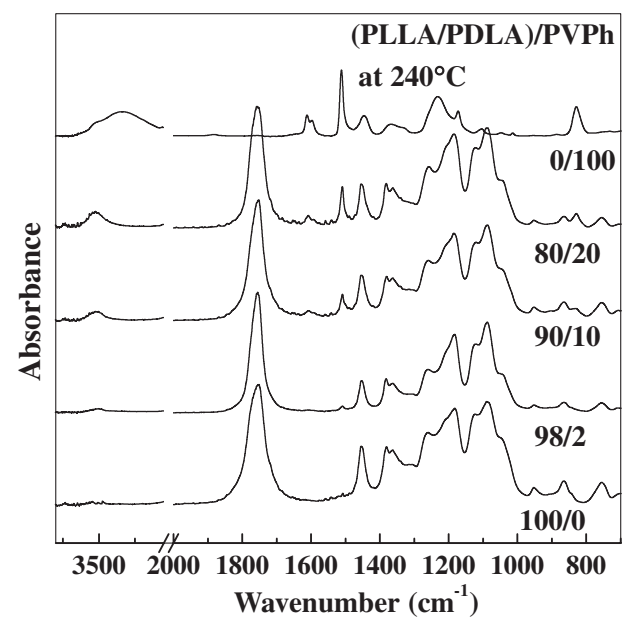

Figure 3. IR spectra in the range $3800-600 \mathrm{~cm}^{-1}$ for (PLLA/PDLA)/PVPh ternary blend of various compositions. All spectra measured at $240^{\circ} \mathrm{C}$, which was above the melting point of stereocomplex.

new hydrogen-bonded $\mathrm{C}=\mathrm{O}$ group formation and no shift in $\mathrm{C}=\mathrm{O}$ stretching bands.

WAXD characterization was performed for all melt-crystallized specimens of the PLLA, (PLLA/PDLA) binary blend and (PLLA/PDLA)/PVPh ternary blends. X-ray diffraction profiles of neat PLLA and the (PLLA/PDLA)/PVPh blends isothermally crystallized at $120^{\circ} \mathrm{C}$ for $4 \mathrm{~h}$ were characterized. For brevity, figure for WAXD result is not shown here. The result showed that the diffraction peaks for (PLLA/PDLA) crystals in these different ternary blends are the same regardless of $\mathrm{PVPh}$ contents. The diffraction peaks for neat PLLA ${ }^{28-31}$ appear at $2 \theta=15^{\circ}, 17^{\circ}$ and $19^{\circ}$, which are comparable with the results for the $\alpha$ form of PLLA crystal. However, quite intense peaks for the complexed (PLLA/PDLA) and (PLLA/PDLA)/PVPh blends are observed at $2 \theta$ of $12^{\circ}, 21^{\circ}$ and $24^{\circ}$ instead, in agreement with the literature result for the PLA stereocomplex crystals. ${ }^{28-31}$ It appears that there is no significant effect on the crystal cell types by adding amorphous PVPh into the (PLLA/ PDLA) complex, and this interpretation is in agreement with the earlier DSC result.

Figure 4 shows polarized optical micrographs of the blends after complete crystallization at $140{ }^{\circ} \mathrm{C}$. It can be seen that the blend without PVPh forms large-size spherulites $(>200 \mu \mathrm{m})$. The presence of $\mathrm{PVPh}$ reduces the spherulites size as is evident from Graphs (b)-(e). No significant difference in the Maltesecross spherulites was observed by increasing the $\mathrm{PVPh}$ content in the blend. However, the nucleation rates significantly increase for blends with adding $\mathrm{PVPh}$.

\section{Kinetic Analysis}

Crystallization kinetics was first determined using isothermal DSC experiments. The isothermal heat flow curves obtained from DSC experiments were integrated to determine the sample crystallinity as a function of time. The percent crystallinity was calculated from the area under the DSC curve from $\mathrm{t}=0$ to $\mathrm{t}$ divided by the full area of the heat flow curve. The crystallization half-time $\left(\mathrm{t}_{0.5}\right)$ defined as the time at which 

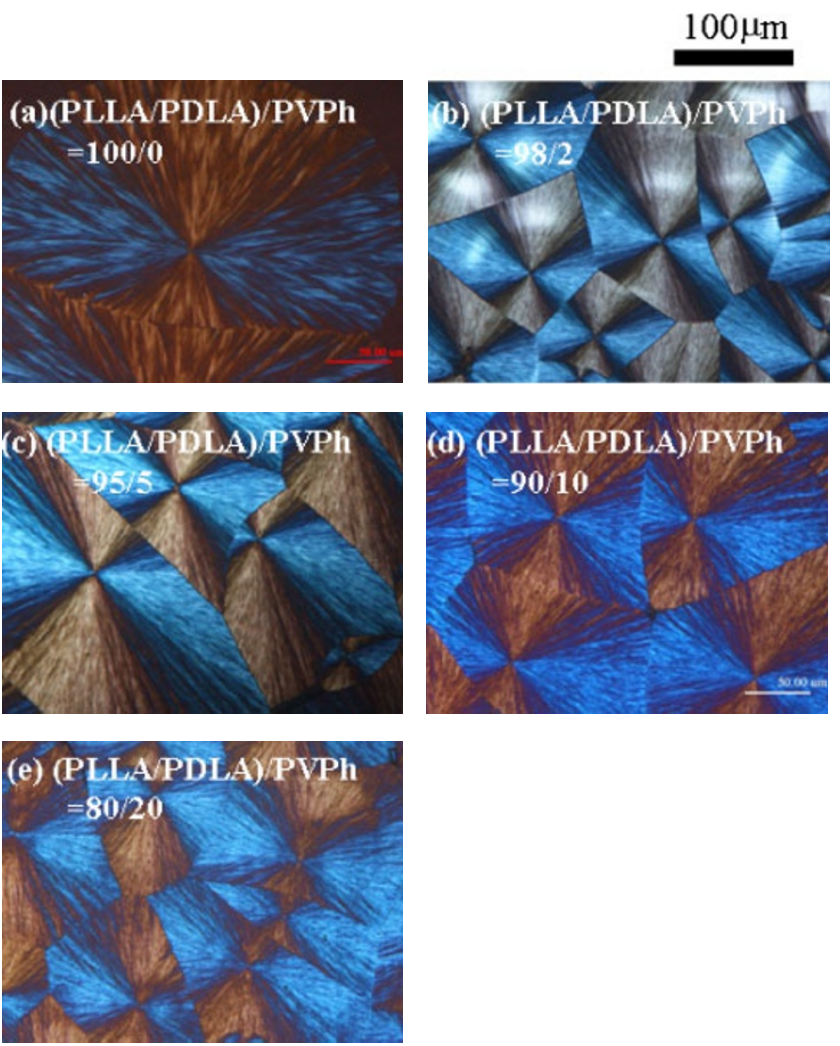

Figure 4. OM graphs of (PLLA/PDLA)/PVPh blend crystallized at $140^{\circ} \mathrm{C}$ : (a) 100/0, (b) 98/2, (c) 95/5, (d) 90/10, and (e) 80/20 (wt. ratio).

the extent of crystallization is $50 \%$. The values of $\mathrm{t}_{0.5}$ (isothermally crystallized at $200{ }^{\circ} \mathrm{C}$ ) were plotted against the PVPh content in Figure 5. It can be seen that the crystallization half-time for the blends with $2-10 \mathrm{wt} \% \mathrm{PVPh}$ is shorter than that for neat PLA complex. However, the crystallization halftime for the blend with $20 \mathrm{wt} \% \mathrm{PVPh}$ increases sharply and is higher than the $\mathrm{t}_{0.5}$ for the neat PLA complex. It is obvious that the crystallization of PLA complex is remarkably affected by $\mathrm{PVPh}$ addition. This suggests that low content of PVPh acts as a heterogeneous nucleation agent and accelerates the crystallization of PLA complexes. Similar results were reported in the literature. Xu et $a l .{ }^{32}$ have reported that epoxy particles act as effective nucleating agents, accelerating the crystallization of poly(butylene terephthalate) (PBT) component in the PBT/ Epoxy blends. An addition of small amount of epoxy resin leads to an increase in the number of effective nuclei, thus resulting in an increase in crystallization rate. Zhang et al. ${ }^{33}$ have reported that the presence of a small amount of hyperbranched polyurethane acrylate (HUA) remarkably influences the crystallizability of polypropylene. An addition of HUA leads to an increase in the number of effective nuclei, thus resulting in an increase of crystallization rate and a clearer trend of instantaneous three-dimensional growth.

Figure 6(a) shows the time-dependent IR spectra in the range of $4000-400 \mathrm{~cm}^{-1}$ during the melt crystallization process of PLLA/PDLA solvent-cast film isothermally kept at $200^{\circ} \mathrm{C}$. The enlarged spectra in the $1000-800 \mathrm{~cm}^{-1}$ region are shown

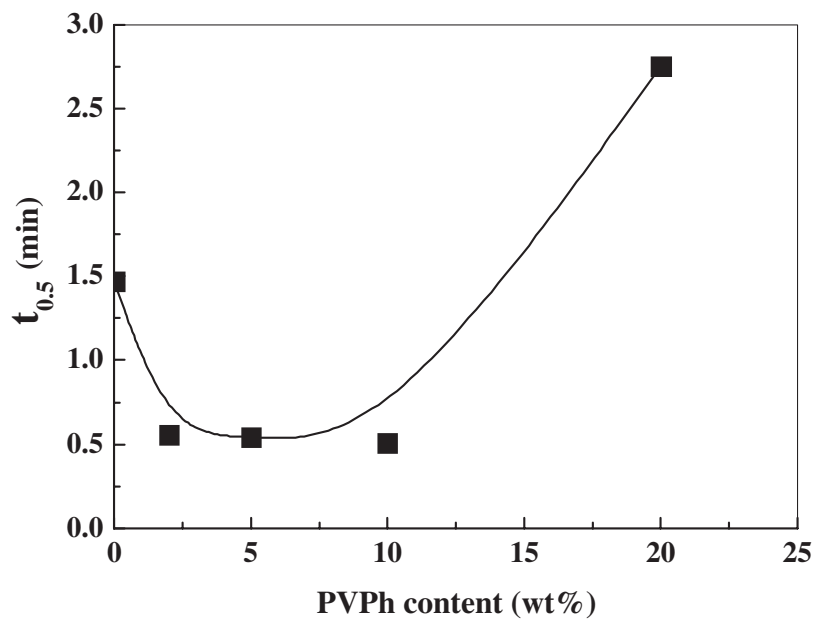

Figure 5. Crystallization half-time as a function of PVPh content in (PLLA) PDLA)/PVPh ternary blends crystallized isothermally at $200^{\circ} \mathrm{C}$.

in Figure 6(b). The result of the blends with 2 and $10 \mathrm{wt} \%$ PVPh are also shown in (c) and (d), respectively. Figure 6(b)6(d) clearly shows a new band at $908 \mathrm{~cm}^{-1}$, which is a characteristic band for identifying the PLA stereocomplexes. ${ }^{31,34-36}$ Figure 6(c) and (d) show that the intensity of the band at $908 \mathrm{~cm}^{-1}$ increases with the annealing time, and this fact indicates that a stereocomplex is being formed during the melt crystallization at $200^{\circ} \mathrm{C}$. By contrast, the blend without $\mathrm{PVPh}$ shows no significant difference indicating the stereocomplex formation in the blend without $\mathrm{PVPh}$ is slower than that in the ternary blends. The results are in good agreement with POM that the growth rate increases by adding PVPh in the system.

Figure 7(a)-7(d) show the nonisothermal crystallization behaviors of the ternary blends of several low PVPh contents at various cooling rates. The crystallization exothermic peak shifts to a lower temperature range with increase of the cooling rate for all blends. At a given cooling rate, the exothermic curve of blends with low content PVPh $(<20 \mathrm{wt} \%)$ shifts to higher temperature range in comparison with that without $\mathrm{PVPh}$, indicating a decrease in nucleation rate of stereocomplex. In addition, all curves have approximately the same sigmoidal shape, indicating that only retardation effect of cooling rate on crystallization is observed. ${ }^{37}$

Figure 8 summarizes the variation of crystallization peak temperature $\left(T_{\mathrm{p}}\right)$ against the cooling rate $(\phi)$ for all blends. For all, $T_{\mathrm{p}}$ shifts to lower temperature with increasing cooling rate. The lower the cooling rate is, the earlier the crystallization starts. The time for PLA complex to crystallize at high crystallization temperature was not long enough with increase in cooling rate, so $T_{\mathrm{p}}$ shifted to low crystallization temperature range. At the same cooling rates, $T_{\mathrm{p}}$ of the blends with low contents of $\mathrm{PVPh}(<20 \mathrm{wt} \%)$ is higher than that of stereocomplex without PVPh. On the other hands, $T_{\mathrm{p}}$ in the blend with high PVPh contents is lower than that without PVPh. Apparently, blending with low PVPh contents accelerates the rates of crystallization of the PLLA/PDLA stereocomplex. 

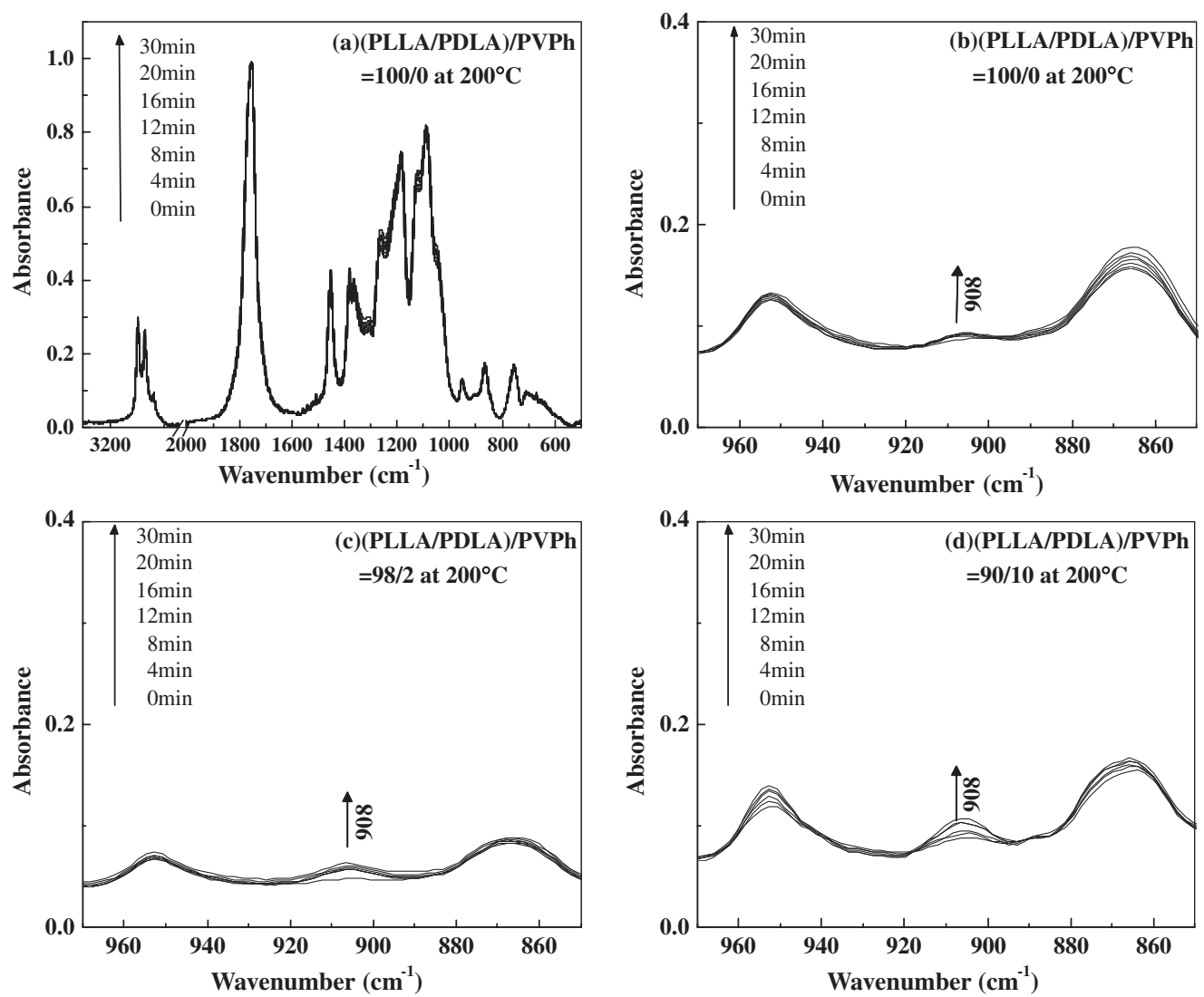

Figure 6. (a) Time-dependent IR spectra in the range of $4000-400 \mathrm{~cm}^{-1}$ collected during the melt crystallization process of the $(\mathrm{PLLA} / \mathrm{PDLA}) / \mathrm{PVPh}=100 / 0$ blend at $200^{\circ} \mathrm{C}$, and $(\mathrm{b}-\mathrm{d})$ time-dependent IR spectra in the range of $970-850 \mathrm{~cm}^{-1}$ collected during the melt crystallization process of the various (PLLA/PDLA)/PVPh blends at $200^{\circ} \mathrm{C}$.
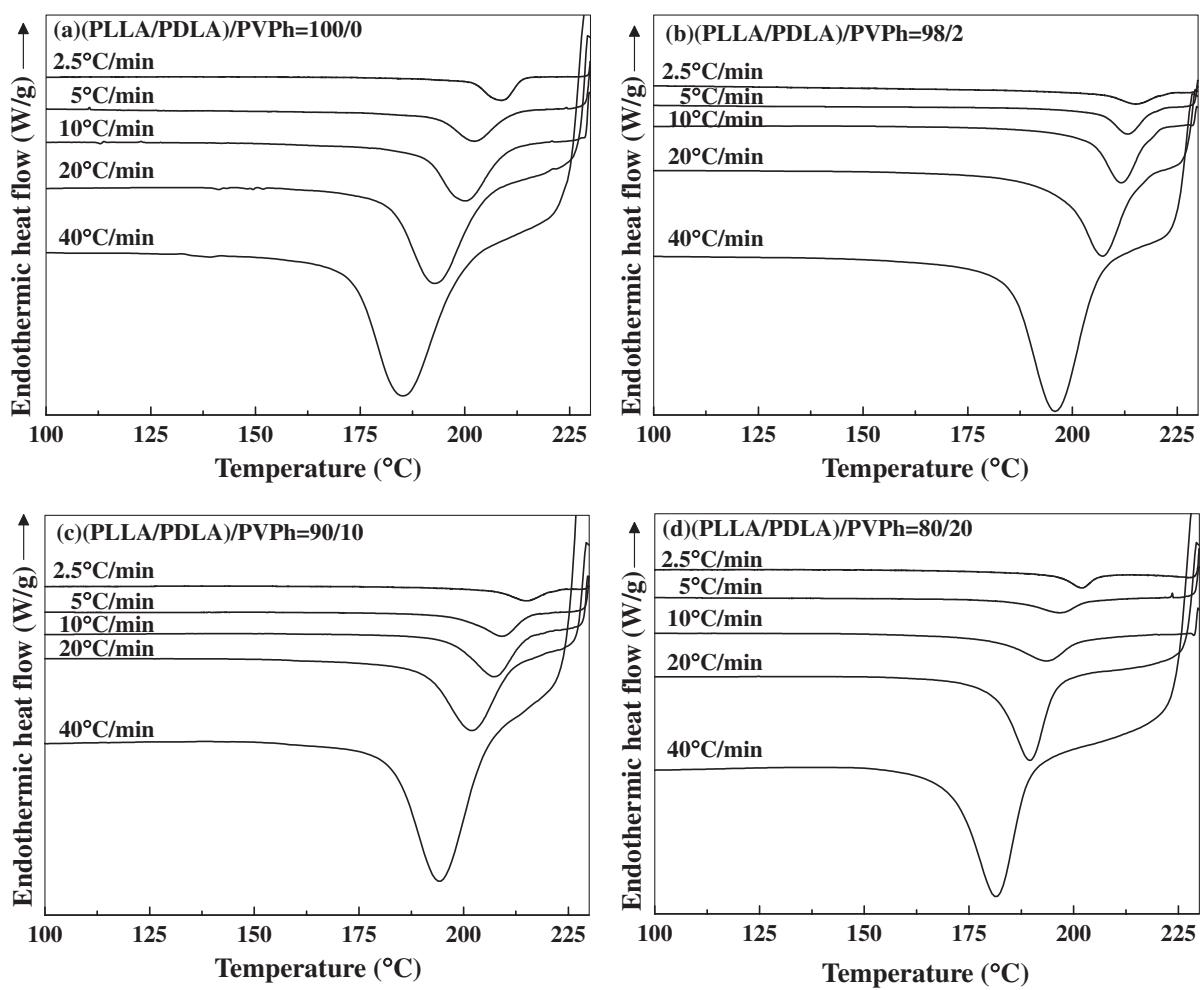

Figure 7. DSC traces at various cooling rate for (PLLA/PDLA)/PVPh ternary blend compositions = (a) 100/0, (b) 98/2, (c) 90/10, and (d) 80/20. 


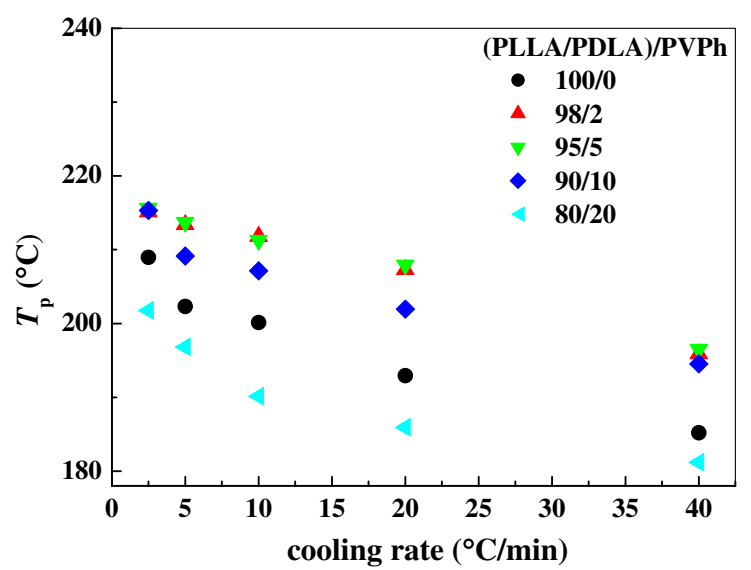

Figure 8. Crystallization peak temperature $\left(T_{\mathrm{p}}\right)$ versus cooling rate $(\phi)$ for (PLLA/PDLA)/PVPh blend of various compositions.

Three methods, namely Avrami, Tobin, and Jeziorny kinetics models, were employed to investigate the kinetics of nonisothermal crystallization in this study. First, the Avrami model ${ }^{38-41}$ was used in this study to compare the crystallization rates of the ternary blends. The Avrami equation is as follows:

$$
X_{\mathrm{t}}=1-\exp \left(-K_{\mathrm{a}} t^{n_{\mathrm{a}}}\right)
$$

where $X_{\mathrm{t}}$ is the relative crystallinity as a function of time, $n_{\mathrm{a}}$ is the Avrami constant depending on the crystal growth mechanism, $t$ is the time, $K_{\mathrm{a}}$ is the rate constant involving both nucleation and growth rate parameters. The double logarithmic form of the equation is

$$
\log \left[-\ln \left(1-X_{\mathrm{t}}\right)\right]=\log K_{\mathrm{a}}+n_{\mathrm{a}} \log t
$$

Plotting $\log \left(-\ln \left(1-X_{\mathrm{t}}\right)\right)$ versus $\log t$ for each cooling rate determines the kinetic constants as shown in Figure 9. The Avrami plots generally fit the experimental data linearly at low degree of crystallinity and derivate from the linear regression at higher crystallization ratio because it possibly does not account for secondary crystallization. The Avrami exponents $n_{\mathrm{a}}$ and $K_{\mathrm{a}}$ were obtained from the slopes and the intercept, respectively.

In nonisothermal crystallization, a temperature change at a given constant cooling rate affects the rates of both nucleation and spherulite growth, which is a temperature-dependent character of the nonisothermal crystallization process. Considering the temperature-dependent character of the nonisothermal crystallization process, Jeziorny ${ }^{42}$ proposed a modified rate parameter, $K_{\mathrm{c}}$, as following:

$$
\ln K_{\mathrm{c}}=\frac{\ln K_{\mathrm{a}}}{\phi}
$$

where $K_{\mathrm{c}}$ is the cooling rate independent rate constant. The Avrami exponents, $n_{\mathrm{a}}$, and the kinetic constants by the Jeziorny method are summarized in Table I. $K_{\mathrm{c}}$ of the blends with low $\mathrm{PVPh}$ contents at a given cooling rate is larger than that of blends without $\mathrm{PVPh}$, indicating a higher crystallization rate in the ternary blends with low PVPh contents. In high $\mathrm{PVPh}$ contents $(20 \mathrm{wt} \%)$, the $K_{\mathrm{c}}$ is lower than those with low PVPh contents, indicating that the high content $\mathrm{PVPh}$ hinders the
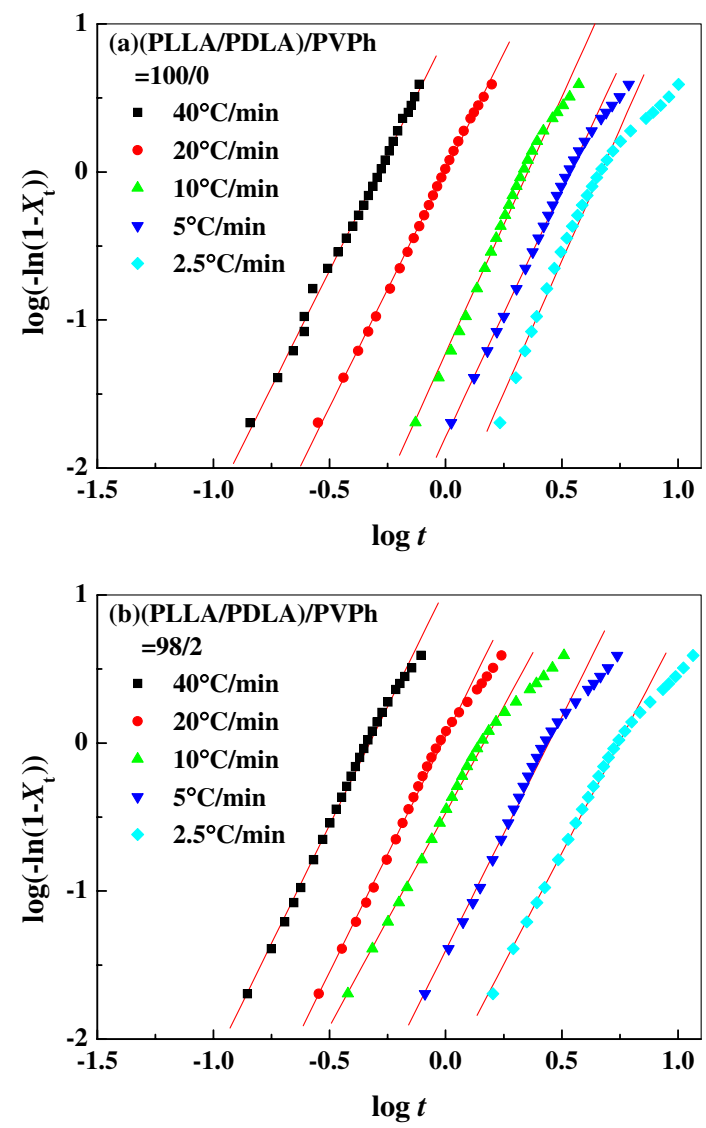

Figure 9. Avrami plots of ternary blend during nonisothermal melt crystallization for (PLLA/PDLA)/PVPh compositions: (a) 100/0, and (b) $98 / 2$.

Table I. Values of $n_{\mathrm{a}}$ and $K_{\mathrm{C}}$ from modified Avrami equation and values of $n_{\mathrm{t}}$ and $K_{\mathrm{t}}$ from Tobin equation for (PLLA/PDLA)/PVPh blend

\begin{tabular}{ccccccccc}
\hline \multirow{2}{*}{$\begin{array}{c}\text { Cooling } \\
\text { rate } \\
\left({ }^{\circ} \mathrm{C} / \mathrm{min}\right)\end{array}$} & \multicolumn{3}{c}{ (PLLA/PDLA)/PVPh $=100 / 0$} & \multicolumn{3}{c}{ (PLLA/PDLA)/PVPh $=98 / 2$} \\
\cline { 2 - 10 } & $n_{\mathrm{a}}$ & $\log K_{\mathrm{c}}$ & $n_{\mathrm{t}}$ & $\log K_{\mathrm{t}}$ & $n_{\mathrm{a}}$ & $\log K_{\mathrm{c}}$ & $n_{\mathrm{t}}$ & $\log K_{\mathrm{t}}$ \\
\hline 2.5 & 3.56 & -0.954 & 4.37 & -2.67 & 3.01 & -0.899 & 3.96 & -2.69 \\
5 & 3.34 & -0.358 & 4.68 & -2.20 & 3.15 & -0.280 & 4.21 & -1.59 \\
10 & 3.46 & -0.122 & 5.08 & -1.43 & 2.88 & -0.047 & 3.79 & -0.36 \\
20 & 3.19 & 0.001 & 4.89 & 0.32 & 3.19 & 0.002 & 4.49 & 0.37 \\
40 & 3.15 & 0.023 & 4.68 & 1.67 & 3.2 & 0.026 & 4.54 & 1.81 \\
\hline
\end{tabular}

Cooling $\quad($ PLLA/PDLA $) / P V P h=90 / 10 \quad($ PLLA $/ P D L A) / P V P h=80 / 20$

\begin{tabular}{ccrrrrrrr}
$\left({ }^{\circ} \mathrm{C} / \mathrm{min}\right)$ & $n_{\mathrm{a}}$ & $\log K_{\mathrm{c}}$ & \multicolumn{1}{c}{$n_{\mathrm{t}}$} & $\log K_{\mathrm{t}}$ & $n_{\mathrm{a}}$ & $\log K_{\mathrm{c}}$ & $n_{\mathrm{t}}$ & $\log K_{\mathrm{t}}$ \\
\hline 2.5 & 3.01 & -0.855 & 4.20 & -2.71 & 3.47 & -1.065 & 5.20 & -3.60 \\
5 & 3.22 & -0.295 & 4.48 & -1.71 & 3.31 & -0.360 & 5.17 & -2.44 \\
10 & 3.1 & -0.049 & 4.58 & -0.41 & 3.41 & -0.099 & 4.95 & -1.04 \\
20 & 3.24 & 0.005 & 4.75 & 0.47 & 3.35 & 0.002 & 4.81 & 0.46 \\
40 & 3.09 & 0.288 & 4.50 & 1.99 & 3.37 & 0.030 & 4.62 & 1.96 \\
\hline
\end{tabular}

growth of stereocomplex under a nonisothermal condition. The result is in good agreement with the plot of $T_{\mathrm{p}}$ versus cooling rate.

The nonisothermal crystallization kinetics of the ternary blends were also studied by the Tobin method, which suggests a theory of phase transformation kinetics with growth site 

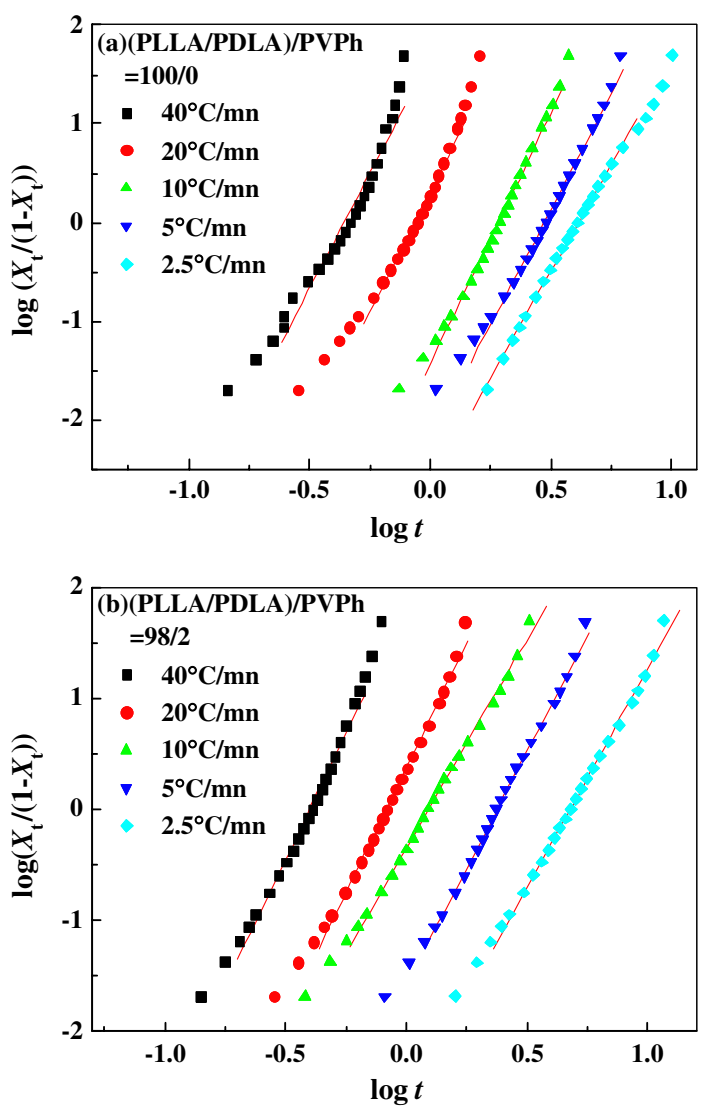

Figure 10. Tobin plots of ternary blend during nonisothermal melt crystallization for (PLLA/PDLA)/PVPh compositions: (a) 100/0 and (b) $98 / 2$.

impingement to describe the nonisothermal crystallization process of polymer. ${ }^{4-46}$ According to this approach, the equation is

$$
X_{\mathrm{t}}=\frac{K_{\mathrm{t}} t^{n_{\mathrm{t}}}}{1+K_{\mathrm{t}} t^{n_{\mathrm{t}}}}
$$

where $K_{\mathrm{t}}$ is the Tobin crystallization rate constant, and $n_{\mathrm{t}}$ is the Tobin exponent. Equation could be rewritten as follows

$$
\log \left[X_{\mathrm{t}} /\left(1-X_{\mathrm{t}}\right)\right]=\log K_{\mathrm{t}}+n_{\mathrm{t}} \log t
$$

According to the treatment using these models, Figure 10 shows the Tobin plots for two blends, from which $n_{\mathrm{t}}$ and $\log K_{\mathrm{t}}$ were obtained and listed in Table I. The other blend compositions reveal the similar phenomena, but they are not shown for brevity. The values of $K_{\mathrm{t}}$ for blended with low PVPh content are higher than those of blend without PVPh at the same cooling rate, indicating that the crystallization of stereocomplex increases in the ternary blend with low PVPh contents. The result is similar to that obtained by the Avrami method.

\section{CONCLUSION}

There is marginal miscibility between PVPh and PLLA/ PDLA as judged by the single composition-dependent glass transition temperature and the negative value of interaction parameter for the blends of low PVPh contents; but phase domains may exist and phase separation takes place when the PVPh contents in the ternary blends are high. At low contents, $\mathrm{PVPh}$ is well dispersed in the ternary blends, which accelerates the crystallization (nucleation rate) and reduces the size of spherulites of the stereocomplex. Furthermore, under nonisothermal process, blending with low $\mathrm{PVPh}$ contents accelerates the ability of stereocomplex crystallization at the same cooling rate. The Avrami and Tobin kinetic analysis methods were carried out to analyze the nonisothermal crystallization data, and the results showed that the ternary blends with an optimal range of $2-10 \mathrm{wt} \% \mathrm{PVPh}$ were faster in the crystallization rate and smaller in the spherulite size than those with no PVPh or with PVPh contents greater than $10 \mathrm{wt} \%$. PVPh may serve as an effective agent in reducing the spherulite sizes of the PLLA/PDLA crystals, which may be useful in controlling the microscopic morphology, crystallization rate, and ultimately the macroscopic properties.

Acknowledgment. This work has been financially supported by a basic research grant (NSC-95 2221 E006 183) in three consecutive years from Taiwan's National Science Council (NSC), to which the authors express their gratitude. In addition, to expand visions and experiences on biomaterials, one of the co-authors, S. H. Li, was trained for two weeks as an international exchange student at Department of Nanostructure and Advanced Materials, Kagoshima University, Kagoshima, Japan, via funding kindly provided by Prof. Yasuo Suda of Venture Business Laboratory (VBL) at Kagoshima U.

Received: August 27, 2008

Accepted: January 20, 2009

Published: March 4, 2009

\section{REFERENCES}

1. R. Marín, A. Martínez de Ilarduya, P. Romero, J. R. Sarasua, E. Meaurio, E. Zuza, and S. Muñoz-Guerra, Macromolecules, 41, 3734 (2008).

2. F. Bosscher, G. Ten Brinke, and G. Challa, Macromolecules, 15, 1442 (1982).

3. K. Koennecke and G. Rehage, Makromol. Chem., 184, 2679 (1983).

4. H. Matsubayashi, Y. Chatani, H. Tadokoro, P. Dumas, N. Spassky, and P. Sigwalt, Macromolecules, 10, 996 (1977).

5. H. Sakakihara, Y. Takahashi, H. Tadokoro, N. Oguni, and H. Tani, Macromolecules, 6, 205 (1973).

6. D. Grenier, R. E. Prud'homme, A. Leborgne, and N. Spassky, J. Polym. Sci., Polym. Phys. Ed., 22, 577 (1984).

7. C. Lavallée and R. E. Prud'homme, Macromolecules, 22, 2438 (1989).

8. Y. Ikada, K. Jamshidi, H. Tsuji, and S.-H. Hyon, Macromolecules, 20 904 (1987).

9. T. Okihara, M. Tsuji, A. Kawaguchi, K.-I. Katayama, H. Tsuji, S.-H. Hyon, and Y. Ikada, J. Macromol. Sci., Phys., B30, 119 (1991).

10. D. Brizzolara, H.-J. Cantow, K. Diederichs, E. Keller, and A. J. Domb, Macromolecules, 29, 191 (1996).

11. H. Tsuji and Y. Tezuka, Biomacromolecules, 5, 1181 (2004).

12. H. Tsuji, Polymer, 43, 1789 (2002).

13. S. Brochu, R. E. Prud'homme, I. Barakat, and R. Jerome, Macro- 
molecules, 28, 5230 (1995).

14. J. Slager and A. J. Domb, Biomaterials, 23, 4389 (2002).

15. J. Slager and A. J. Domb, Biomacromolecules, 4, 1316 (2003).

16. J. Slager and A. J. Domb, Eur. J. Pharm. Biopharm., 58, 461 (2004).

17. A. Bishara and A. J. Domb, J. Controlled Release, 107, 474 (2005).

18. H. Tsuji, Macromol. Biosci., 5, 569 (2005).

19. K. Fukushima, Y.-H. Chang, and Y. Kimura, Macromol. Biosci., 7, 829 (2007).

20. L. Zhang, S. H. Goh, and S. Y. Lee, Polymer, 39, 4841 (1998).

21. E. Meaurio, E. Zuza, and J. R. Sarasua, Macromolecules, 38, 1207 (2005).

22. E. Meaurio, E. Zuza, and J. R. Sarasua, Macromolecules, 38, 9221 (2005).

23. J. D. Hoffman and J. J. Weeks, J. Res. NBS, A. Phys. Chem., 66A, 113 (1962).

24. P. J. Flory, "Principles of Polymer Chemistry," Cornell U. Press, Ithaca, 1978, Chap. XII.

25. T. Nishi and T. T. Wang, Macromolecules, 8, 909 (1975).

26. C. J. T. Landry, D. J. Massa, D. M. Teegarden, M. R. Landry, P. M. Henrichs, R. H. Colby, and T. E. Long, Macromolecules, 26, 6299 (1993).

27. S. W. Kuo, C. F. Huang, and F. C. Chang, J. Polym. Sci., Part B: Polym. Phys., 39, 1348 (2001).

28. H. Tsuji and Y. Ikada, Polymer, 40, 6699 (1999).

29. Y. Ikada, K. Jamshidi, H. Tsuji, and S. H. Hyon, Macromolecules, 20,
904 (1987).

30. J. R. Sarasua, R. E. Prud'homme, M. Wisniewski, A. Le Borgne, and N. Spassky, Macromolecules, 31, 3895 (1998).

31. G. Kister, G. Cassanas, and M. Vert, Polymer, 39, 267 (1998).

32. G. Xu, W. F. Shi, P. Hu, and S. P. Mo, Eur. Polym. J., 41, 1828 (2005).

33. H. Zhang, M. Ren, Q. Chen, S. Sun, X. Sun, H. Zhang, and Z. Mo, J. Polym. Sci., Part B: Polym. Phys., 44, 1320 (2006).

34. J. Zhang, H. Sato, H. Tsuji, I. Noda, and Y. Ozaki, Macromolecules, 38, 1822 (2005).

35. D. Qin and R. T. Kean, Appl. Spectrosc., 52, 488 (1998).

36. S. Kang, S. L. Hsu, H. D. Stidham, P. B. Smith, M. A. Leugers, and X. Yang, Macromolecules, 34, 4542 (2001).

37. Q. Ding, W. L. Dai, and P. Zhang, Polym. Eng. Sci., 47, 2034 (2007).

38. I. Acar, A. Durmuş, and S. Özgümüş, J. Appl. Polym. Sci., 106, 4180 (2007).

39. M. Avrami, J. Chem. Phys., 7, 1103 (1939).

40. M. Avrami, J. Chem. Phys., 8, 212 (1940).

41. M. Avrami, J. Chem. Phys., 9, 177 (1941).

42. A. Jeziorny, Polymer, 19, 1142 (1978).

43. Z. Qiu and W. Yang, J. Appl. Polym. Sci., 104, 972 (2007).

44. M. C. Tobin, J. Polym. Sci., Polym. Phys. Ed., 12, 399 (1974).

45. M. C. Tobin, J. Polym. Sci., Polym. Phys. Ed., 14, 2253 (1976).

46. M. C. Tobin, J. Polym. Sci., Polym. Phys. Ed., 15, 2269 (1977). 